Poul Erik Flyvholm Jørgensen \& Anna Trosborg*

\title{
Introduction: \\ Exploring genres of professional communication
}

This thematic section of Hermes contains contributions from seven scholars participating in the $4^{\text {th }}$ European Convention of the Association for Business Communication (ABC) held at the Aarhus School of Business in May 2002. The convention was themed on the principles of business communication "across contexts, cultures and continents", and the contributors have in different ways attempted to chart and explain language use and the underlying discursive choices of professionals and business executives producing a variety of genres. The present selection of articles clearly illustrates how genre analysts today exploit a mixture of research methods and approaches in an unprejudiced fashion to account for the broad range of factors influencing professional message production. Their expositions not only focus on relevant aspects of research methodology but also highlight important teaching implications for instructors in the field. Due to editorial pressures, Lise Mourier's article about the requirements to financial reporting prepared in English by Danish companies, which belongs to the present collection, will appear in the next issue of Hermes (February 2004).

Sonja Vandermeeren illustrates how a company's requirement for communicative competence in a foreign language can be arranged into categories covering objective, subjective or unconscious need. Rather than asking the management or staff of a company about their actual and perceived foreign language needs, she turns the table to conduct a series of interviews with their foreign business partners in order to capture how they perceive the communicative skills of the other company's sales

\footnotetext{
* Poul Erik Flyvholm Jørgensen \& Anna Trosborg

Engelsk Institut

Handelshøjskolen i Arhus

Fuglesangs Allé 4

DK-8210 Arhus $V$
} 
managers, marketing employees, etc. Interestingly, the study shows that German companies are not particularly concerned about the German proficiency of their Danish business partners but attach considerable importance to their knowledge of German corporate culture and cross-cultural adaptability. Thus, she argues that company representatives are required to know the non-linguistic sales techniques of the foreign business culture just as much as they are expected to be familiar with their partners' corporate tactics of communication. Vandermeeren not only makes the didactic observation that teachers of business communication require remedies to develop their students' intercultural sensitivity and skills but also suggests what these might consist of.

In explaining the construction and use of a new institutional genre, Karsten Pedersen conducts a case study of the so-called 'service information pamphlets' distributed by Danish local and regional authorities. These pamphlets are produced locally by council authorities in accordance with an Act of Parliament to provide for improved citizens' information about public services and local government objectives and priorities. Pedersen supplements his text-based study with a top-down inquiry both into the actual production of the pamphlets by county officials and into the reception of the pamphlets by local citizens. To do this, he performs extensive interviews with both message recipients and producers, studies official guidelines for the production of the pamphlets, compares choices and procedures across several different Danish councils, confronts informants with real and made-up text exemplars, and is thus able to qualify his text-based findings concerning the construction of a new genre.

Margrethe Mondahl and Lisbet Pals Svendsen discuss their ongoing research designed to clarify how competently Danish MA students of English employ information processing strategies to solve oral translation tasks and the degree to which the acquired competencies become more or less permanently internalised. To do this, they rely on a range of research approaches, combining and reaping the benefits of qualitative and quantitative methods. By videoing their students' performances and self-reflective discussions over a period of fifteen months and by intermittently administering questionnaires to students, Mondahl and Pals Svendsen could quantitatively assess performances and collect a variety of both introspective and retrospective data. This allowed them to begin to track developments across five communicative competence areas given 
special focus within their teaching programme. Importantly, their early results give indication that students of English as a foreign language focus on the choice of discursive and strategic resources at the expense of grammatical input. Mondahl and Pals Svendsen take departure in three different models which capture supplementary aspects of learners' competencies.

Hilkka Yli-Jokipii focuses on the two genres of book information and place description in order to explore alternative uses of adjectival modification in these text types which differ through the two fundamentally competing purposes of persuasion and description, respectively. As opposed to the three previous contributions in this section, she takes a bottom-up approach in seeking to pin down the different roles and significance of modifying adjectives in varieties of non-fictional discourse. This is done in the study by dividing modifying adjectives into four different classes which are, in turn, used to explain the various communicative functions they serve. On the basis of the analysis of a sample of eight texts in which she combines quantitative and qualitative methods, Yli-Jokipii concludes that adjectival modifiers are used with similar frequency in the two genres investigated and that the established frequency is neither exclusively linked to writers' use of nominal style nor in a direct ratio to lexical density, contrary to what might be expected. Thus, the study strongly suggests that the use of adjectival modifiers is not a characteristic which separates persuasive text types from descriptive ones.

In order to meet the growing requirement for improved grammar skills from both employers of graduates and technology programme faculty, Kathleen Vance has developed an intensive grammar course for engineering technology students designed to avoid a number of the traditional pitfalls which commonly give poor results and frustrated course participants. The contents of the eight mini grammar lessons in the course were determined by counting and categorising the errors found in a set of student exam papers. In order to improve student satisfaction and competence, the lessons were developed to specifically deal with the topics, documents and tasks already familiar to the student of a particular technology area and were designed to be delivered by means of a commercially available software programme (WebCT). This programme offers various interactive features and resources useful for the specific purposes 
12

of evaluation and feedback. Essential to the success of the programme was the individual student's self-reflective praxis as a learner, recognition of his or her own communicative needs and requirements, and improvement of status and self-esteem with respect to linguistic skills. Vance rates the success of the web-facilitated mini grammar lessons by administering questionnaires to her students and by performing a qualitative assessment of student responses. In spite of several clear advantages over traditional sentence-based text-book teaching of grammar, Vance recognises that there is still a considerable spillover effect from this medium which requires remedying action through increased contextualisation of the mini grammar lessons, e.g. facilitated via group work and peer editing.

Finally, Paul Gillaerts has examined the persuasive text genre of job applications to establish possible links between negative/positive recruiter evaluations and the distinctive rhetorical and metadiscursive features of applications. Gillaerts made the early observation that the recruitment officers in his study were struggling to comment on how their assessments of individual applications were determined by aspects of form as opposed to context-related phenomena. Thus, the study was instead performed in a bottom-up fashion by examining a corpus of solicited and unsolicited job applications to determine which features were related to the degree of persuasiveness already given to the applications by the informants. The adopted approach is qualitative, and Gillaerts argues that a straightforward quantification of the rhetorical and metadiscursive elements of a text is problematic insofar as each element may serve multiple persuasive purposes. The study shows that a carefully balanced mixture of these elements is crucial to the success of a job application. 